Journal of Applied Pharmaceutical Science Vol. 6 (10), pp. 124-131, October, 2016

Available online at http://www.japsonline.com

DOI: $10.7324 / \mathrm{JAPS} .2016 .601017$

ISSN 2231-3354 (cc) BY-NC-SA

\title{
Formulation and Evaluation of Solid Lipid Nanoparticle (SLN) Based Topical Gel of Etoricoxib
}

\author{
Roohi Kesharwani ${ }^{1 *}$, Anupam Sachan ${ }^{1}$, Swati Singh ${ }^{1}$, Dilip Patel ${ }^{2}$ \\ ${ }^{1}$ Dayanand Dinanath College, Institute of Pharmacy, Kanpur, India. \\ ${ }^{2}$ Department of Pharmaceutical Sciences, SHIATS, Allahabad, U.P., India.
}

\begin{tabular}{|c|c|}
\hline ARTICLE INFO & ABSTRACT \\
\hline Article history: & \multirow{11}{*}{$\begin{array}{l}\text { The objective of present investigation was to prepare \& evaluate solid lipid nanoparticle (SLN) based topical gel } \\
\text { of non- steroidal anti-inflammatory drug (NSAID) etoricoxib for the treatment of arthritis which would attenuate } \\
\text { the gastrointestinal related toxicities associated with oral administration. SLN were formulated by melt } \\
\text { emulsification and solidification at low temperature method using stearic acid \& tween } 80 \text {. All the formulation } \\
\text { were subjected to particle size, particle size distribution, zeta potential, scanning electron microscopy, } \\
\text { crystallinity study by DSC and in-vitro release studies. It has been observed that, the high lipid concentration } \\
\text { containing formulation have higher entrapment as compare to other two formulation. The SLN- dispersion } \\
\text { shows } 70.766 \% \text { entrapment \& zeta potential of the formulation were - } 25.6 \text { which indicates the stability of } \\
\text { formulation. The In Vitro drug release rate of gel was evaluated using Modified franz diffusion cell containing } \\
\text { dialysis membrane with phosphate buffer pH 7.4 as the receptor medium. The in-vitro release was carried out in } \\
\text { comparison with a carbopol gel \& hydroxypropylmethylcellulose (HPMC) gel. The permeability parameters } \\
\text { steady-state flux (Jss) was significantly increased in SLN-F3C (carbopol) formulation as compared with SLN- } \\
\text { F3HPMC (hydroxypropyl methylcellulose) formulation. It was concluded that the Etoricoxib loaded SLN based } \\
\text { gel formulation containing carbopol was suitable for topical application and shows much better result of anti- } \\
\text { inflammatory activity. }\end{array}$} \\
\hline Received on: $04 / 04 / 2016$ & \\
\hline Revised on: 18/05/2016 & \\
\hline Accepted on: 01/07/2016 & \\
\hline Available online: $29 / 10 / 2016$ & \\
\hline Key words: & \\
\hline & \\
\hline gel, diffusion cell. & \\
\hline & \\
\hline & \\
\hline & \\
\hline
\end{tabular}

\section{INTRODUCTION}

Etoricoxib is a COX-2 selective inhibitor which selectively inhibits isoform 2 of the enzyme cyclooxygenase (COX-2) which reduces the generation of prostaglandins (PGs) from arachidonic acid (Takemoto et al., 2008). It is a potent analgesic, antipyretic and anti-inflammatory agent has been approved for significantly reduces joint inflammation, pain intensity and the duration of morning stiffness and improved handgrip strength (Gonzalez et al., 1994). An arthritic condition demands a controlled release drug delivery system for a prolong

\footnotetext{
* Corresponding Author

Email: roohi4mail @gmail.com
}

period so that can satisfy the goals of the treatment like reduction of the pain and inflammation, slowing the disease progression and prevention of adverse reaction. The requirement for designing of a topical drug delivery system of etoricoxib, which could not only increase the presence of the drug locally and for a prolonged period but also reduce the risk of systemic toxicity (Lee et al., 2005). Colloidal particles ranging in size between 10 and $1000 \mathrm{~nm}$ are known as nanoparticles. They are manufactured from synthetic/natural polymers and ideally suited to optimize drug delivery and reduce toxicity. Over the years, they have emerged as a variable substitute to liposomes as drug carriers. The successful implementation of nanoparticles for drug delivery depends on their ability to penetrate through several anatomical barriers, sustained release of their contents and their stability in the nanometer size (Westesen et al., 2000; Mukherjee et al., 2009). 
Solid lipid nanoparticles (SLN) introduced in 1991 represent an alternative carrier system to tradition colloidal carriers such as emulsions, liposomes and polymeric micro and nanoparticles. Nanoparticles made from solid lipids are attracting major attention as novel colloidal drug carrier for intravenous applications as they have been proposed as an alternative particulate carrier system. SLN are sub-micron colloidal carriers ranging from 50 to $1000 \mathrm{~nm}$, which are composed of physiological lipid, dispersed in water or in aqueous surfactant solution. SLN offer unique properties such as small size, large surface area, high drug loading and the interaction of phases at the interface and are attractive for their potential to improve performance of pharmaceuticals (Ekambaram et al., 2012).

\section{MATERIALS AND METHODS}

Etoricoxib was received as a gift sample from Unison Pharmaceuticals, Baddi, INDIA, Carbopol 934, HPMC were kindly provided by Guapha Pharmaceuticals, M.P., INDIA, Stearic acid, Isopropyl Myristate, Tween 80 \& Glycerol were purchased from Fizmerk Chemicals, U.P., INDIA, Dialysis membrane was purchased from Hi Media Laboratories Pvt. Ltd., Mumbai. All the reagents and solvents were of analytical reagent (AR) grade.

\section{Preparation of Etoricoxib loaded SLN dispersion}

SLNs loaded with Etoricoxib were prepared using melt emulsification and low-temperature Solidification method. Etoricoxib was dissolved in methanol and mixed with acetone solution containing stearic acid. The mixtures were sonicated for 15 minute, and then added drop wise to Tween 80 solution, stirred at $3000 \mathrm{rpm}$ for $0.5 \mathrm{~h}$ at $70{ }^{\circ} \mathrm{C}$ temperature. The mixed solution was transferred to icy water bath and stirring for four hour at 3000 rpm. Different formulations of drug loaded SLN were prepared by varying concentrations of stearic acid as shown in the below [Table 1] and these SLN dispersions used for further study (Dongfei et al., 2010; Jain et al., 2009).

Table 1: Composition of different SLN dispersion.

\begin{tabular}{cccc}
$\begin{array}{c}\text { Formulation } \\
\text { code }\end{array}$ & $\begin{array}{c}\text { Amount of } \\
\text { drug } \\
(\mathbf{m g})\end{array}$ & $\begin{array}{c}\text { Amount of } \\
\text { Stearic Acid } \\
(\mathbf{m g})\end{array}$ & $\begin{array}{c}\text { Amount of } \\
\text { Tween 80 } \\
(\%)\end{array}$ \\
\hline Blank SLN & ---- & 1000 & 2.5 \\
SLN-F1 & 100 & 1000 & 2.5 \\
SLN-F2 & 100 & 1250 & 2.5 \\
SLN-F3 & 100 & 1500 & 2.5 \\
SLN-F4 & 100 & 1000 & 2.0 \\
SLN-F5 & 100 & 1250 & 2.0 \\
SLN-F6 & 100 & 1500 & 2.0 \\
\hline
\end{tabular}

\section{Characterization of Etoricoxib Loaded SLN Dispersion}

The SLNs characterization parameter like Particle size and size distribution, zeta potential, drug entrapment efficiency (EE), scanning electron microscopy (SEM), FTIR, differential scanning calorimeter analysis (DSC) are described below:

\section{Particle size, Particle size Distribution \& Zeta potential}

The mean particle size and polydispersity index of SLN for size distribution was measured using Malvern Mastersizer 2000MU (Malvern instrument UK). The obtained data were evaluated using the volume distribution $\left(\mathrm{d}_{10 \%}, \mathrm{~d}_{50 \%}, \mathrm{~d}_{90 \%}\right)$. The PI was measured by the span which can be calculated from the following equation.

$$
S P A N=\frac{D 90 \%-D 10 \%}{D 50 \%}
$$

Where $\mathrm{d}_{90 \%}$ is the particle diameter at $90 \%$ cumulative size, $\mathrm{d}_{10 \%}$ is the particle diameter at $10 \%$ cumulative size, and $\mathrm{d}_{50 \%}$ is the particle diameter at $50 \%$ cumulative size (Teeranachaideekul et al., 2007; Sanad et al., 2010; Patel et al., 2012). Zeta potential of SLNs was measured by using Zetasizer 2000 (Malvern Instruments, UK) at $25^{\circ} \mathrm{C}$.

\section{Drug entrapment efficiency}

The entrapment efficiency (EE), which corresponds to the percentage of Etoricoxib encapsulated within and adsorbed on to the nanoparticles, was determined by measuring the concentration of free Etoricoxib in the dispersion medium A volume of $2.0 \mathrm{ml}$ of each drug-loaded sample was centrifuged at $5300 \mathrm{rpm}$ for $70 \mathrm{~min}$ to separate the lipid and aqueous phase. The supernatant was then diluted with methanol and analyzed by UVVIS spectrophotometer at $233 \mathrm{~nm}$ using a Model- 1371, Electronics India. The entrapment efficacy of nanoparticle was calculated as follows:

$$
E E=\left(\frac{W a-W s}{W a}\right) \times 100
$$

Where EE is entrapment efficiency, Wa stands for the mass of Etoricoxib added to the formulation and Ws is the analyzed weight of drug in supernatant (Doktorovova et al., 2010).

\section{Scanning Electron Microscopy}

The morphological characteristic of SLN was determined by scanning electron microscope (JEOL-JSM-6360 JAPAN). One drop of sample was placed on a slide and excess water was left to dry at room temperature. then the slide was attached to the specimen holder using a double coated adhesive tape and gold coated under vacuum using a sputter coater (Model JFC-1100, Jeol, JAPAN)for 10 minute and investigated at $20 \mathrm{kV}$ (Nasr et al., 2008).

\section{Infrared spectroscopy (FTIR)}

Physicochemical characterization was performed using Fourier transform infrared (FTIR) spectroscopy. For this purpose, sample were analysed as $\mathrm{KBr}$ pellets by using a FTIR spectrometer (Shimadzu Corporation, Japan).

\section{Differential Scanning Calorimeter Analysis (DSC)}

The sample were analysed by using differential scanning calorimeter (Model- Perkin Elmer DSC) as a constant scanning 
speed of $10^{0} \mathrm{c} \min ^{-1}$ from $20-220{ }^{\circ} \mathrm{C}$. The $5-7 \mathrm{mg}$ sample was heated in aluminum pans using dry nitrogen as the effluent gas. (Bhaskar et al., 2009).

\section{Formulation of Etoricoxib Loaded SLN Based Gel}

SLN gel was prepared in following manner, required quantity of carbopol 934 and hydroxypropylmethyl cellulose (HPMC) were weighed and dispersed in small quantity of distilled water to prepare aqueous dispersion, and the dispersion was allowed to hydrate for 4 to 5 hour. Glycerol $(10 \% \mathrm{w} / \mathrm{w})$ was added subsequently to the aqueous dispersion equivalent to $1 \%$ of Etoricoxib was incorporated in it. Triethanolamine was added to the above dispersion using an overhead stirrer at speed of 1200 rpm (Singhla Scientific Industries). Stirring was continued till the carbopol get dispersed. The gel was allowed to stand overnight to remove entrapped air (Lala et al., 2014; Bhalekar et al., 2009; Joshi et al., 2008; Sanad et al., 2010).

Table 2: Composition of SLN Gel formulation.

\begin{tabular}{clcc}
\hline S. & \multicolumn{1}{c}{ Composition In \% W/W } & $\begin{array}{c}\text { FORMULATION CODE } \\
\text { SLN-Gel } \\
\text { Carbopol } \\
\text { (C) }\end{array}$ & $\begin{array}{c}\text { SLN-Gel } \\
\text { Hydroxypropyl } \\
\text { methyl Cellulose } \\
\text { (HPMC) }\end{array}$ \\
\hline 1 & Carbopol934/HPMC & 1 & 1 \\
2 & SLN eq to 1\% of Etoricoxib & 1 & 1 \\
3 & Glycerin & 10 & 10 \\
4 & Triethanolamine & q.s. & q.s. \\
5 & Distilled water & q.s. & q.s. \\
\hline
\end{tabular}

\section{EVALUATION OF ETORICOXIB LOADED SLN GEL}

\section{Physical appearance \& Homogeneity}

Physical appearance and homogenecity of gel was observed visually.

\section{Spreadibility study of SLN gel}

The spreadibility of the gel formulations was determined using an apparatus modified in the laboratory. The apparatus was made with two glass plate and glass plate having a pan mounted on pulley.Excess amount of gel was placed between glass slide $(10 \mathrm{x}$ $10 \mathrm{~cm}^{2}$ ). A weight of $100 \mathrm{~g}$ was placed on the upper glass plate for 5 min to compress the formulation. The $100 \mathrm{~g}$ weight tied was added on the pan. The time in seconds required to separate the slides was taken as the measure of spreadability. The spreadibility was calculated by using the following formula.

$$
\mathrm{S}=\mathrm{M} \times \frac{\mathrm{L}}{\mathrm{t}}
$$

Where $\mathrm{S}$ is spreadibility, $\mathrm{M}$ is weight tied on upper slide. $\mathrm{L}$ is the length of glass slide, $\mathrm{t}$ is time taken (Biswal et al., 2014).

\section{In-vitro drug release studies of SLN Based gel}

The In Vitro release studies were performed using modified franz diffusion cell to evaluate the amount of Etoricoxib released from each formulation. Franz glass structure is represented in given Fig.1. These cells consist of donor

compartment, acceptor compartment, Dialysis membrane 70, magnetic stirring, thermostatic water bath and sampling device.

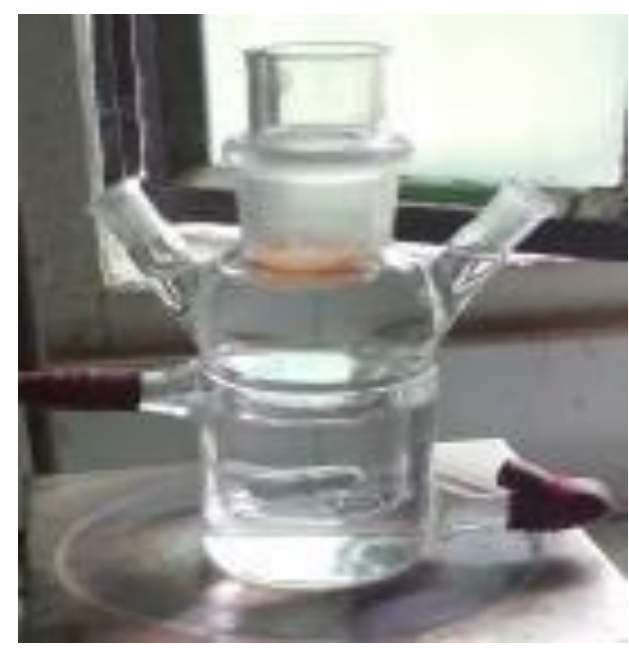

Fig. 1: Modified Franz Diffusion Cell.

Dialysis membrane 70 (Hi-Media, Mumbai, India) having pore size $2.4 \mathrm{~nm}$, molecular weight cut-off between 12,000-14,000 was used and mounted on the Franz diffusion cells. The surface area of the release membrane was $3.14 \mathrm{~cm}^{2}$. The receptor medium was approximately $45 \mathrm{ml}$ and composed of phosphate buffer saline (PBS), $\mathrm{pH} 7.4$, and stirred by magnetic bar at $700 \mathrm{rpm}$ to avoid different concentrations within the acceptor medium and to minimize stagnant layers. SLN Based gels (equivalent to $1 \mathrm{mg}$ of drug) were placed in the donor compartment. During the experiments, the solution in receptor side was maintained at $37{ }^{\circ} \mathrm{C} \pm 0.5{ }^{\circ} \mathrm{C}$.

After certain time interval, 3-mL of the sample medium were withdrawn from receiver compartment through side tube and same volumes of freshly prepared receptor medium were added. The samples were analyzed by UV-VISIBLE spectrophotometer at $233 \mathrm{~nm}$. For each formulation, the release studies were performed in triplicate (Mazumder et al., 2009; Sachan et al., 2009).

\section{Permeation Data Analysis}

The permeation profiles were constructed by plotting the cumulative amount of etoricoxib permeated per unit dialysis membrane area $(\mu \mathrm{g} / \mathrm{cm} 2)$ versus time. The steady state flux (Jss, $\mu \mathrm{g} / \mathrm{cm} 2 / \mathrm{hr}$ ) (Edwards et al., 1994) of etoricoxib was calculated from the slope of the plot using linear regression analysis.

\section{Release Kinetics}

Data obtained from In Vitro release studies were fitted to various kinetic equations to find out the mechanism of drug release from the SLN the dissolved amount of drug (M) is a function of the time $(\mathrm{t})$, or $\mathrm{M}=\mathrm{f}(\mathrm{t})$. In order to analyze the drug release mechanism, the ata is fitted in zero order, first order, Higuchi model. 


\section{RESULT \& DISCUSSION}

\section{Particle size, Particle size distribution \& Zeta potential}

The $\mathrm{d}_{90}$ for SLN F1, F2, F3, F4, F5, F6 and Blank SLN determined using Malvern Mastersizer showed size 1527, 2241, 334, 7232, 1286, 4264 and 16729 nanometer respectively. The particle sizes of formulations were increases as the concentration of tween 80 decreases as shown in table 3 .

The zeta potential of the SLN dispersion is given in the table 3. Zeta potential of blank SLN was -27.2 while for SLN-F3 $\&$ SLN-F6 dispersion it was $-25.6 \&-21.5$. The presence of drug causes a diminution of surface charge of all the investigated samples because probably a share of drug is situated on the lipid nanoparticles surface.

\section{Drug entrapment efficiency}

From the results given in table 3 , it has been observed that, the high lipid concentration containing formulation SLN-F3 have higher entrapment as compare to other formulations. The SLN-F3 dispersion has $70.766 \%$ entrapment, while SLN-F1 \& SLN-F2 have $61.583 \%$ \& $67.366 \%$ respectively. Same as seen in SLN-F6 as compare to SLN-F4 \& SLN-F5.

Table 3: Particle size distribution, zeta potential \& entrapment efficiency of different formulations of SLN.

\begin{tabular}{|c|c|c|c|c|c|c|}
\hline \multirow[t]{2}{*}{ Formulation code } & \multicolumn{3}{|c|}{ Mean volume distribution } & \multirow[t]{2}{*}{ Span } & \multirow{2}{*}{$\begin{array}{l}\text { Zeta potential of SLN } \\
\text { Dispersion }(\mathrm{mV})\end{array}$} & \multirow{2}{*}{$\begin{array}{l}\text { Percentage Entrapment } \\
\text { efficiency* }\end{array}$} \\
\hline & $d_{10 \%}$ & $\mathbf{d}_{50 \%}$ & $\mathbf{d}_{90 \%}$ & & & \\
\hline $\begin{array}{l}\text { SLN-F1 } \\
\end{array}$ & 0.127 & 0.175 & 1.527 & 7.983 & -22.9 & $61.583 \pm 0.897$ \\
\hline SLN-F2 & 0.126 & 0.171 & 2.241 & 0.673 & -24.1 & $67.366 \pm 1.934$ \\
\hline SLN-F3 & 0.126 & 0.171 & 0.334 & 0.633 & -25.6 & $70.766 \pm 1.450$ \\
\hline SLN-F4 & 0.248 & 0.328 & 7.232 & 21.292 & -20.2 & $59.542 \pm 0.824$ \\
\hline SLN-F5 & 0.124 & 0.202 & 1.286 & 5.752 & -20.8 & $65.322 \pm 1.947$ \\
\hline SLN-F6 & 0.126 & 0.324 & 4.264 & 12.771 & -21.5 & $68.732 \pm 1.440$ \\
\hline B-SLN (Blank) & 0.132 & 0.202 & 16.729 & 82.105 & -27.2 & $\ldots \ldots \ldots$ \\
\hline
\end{tabular}

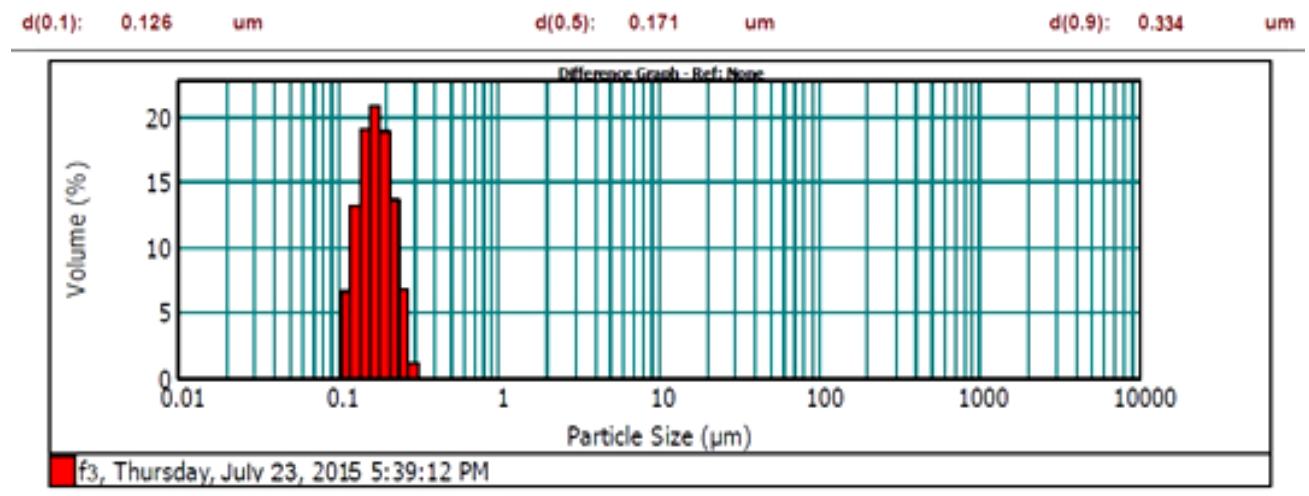

Fig. 2: Particle size distribution graph of SLN-F3.

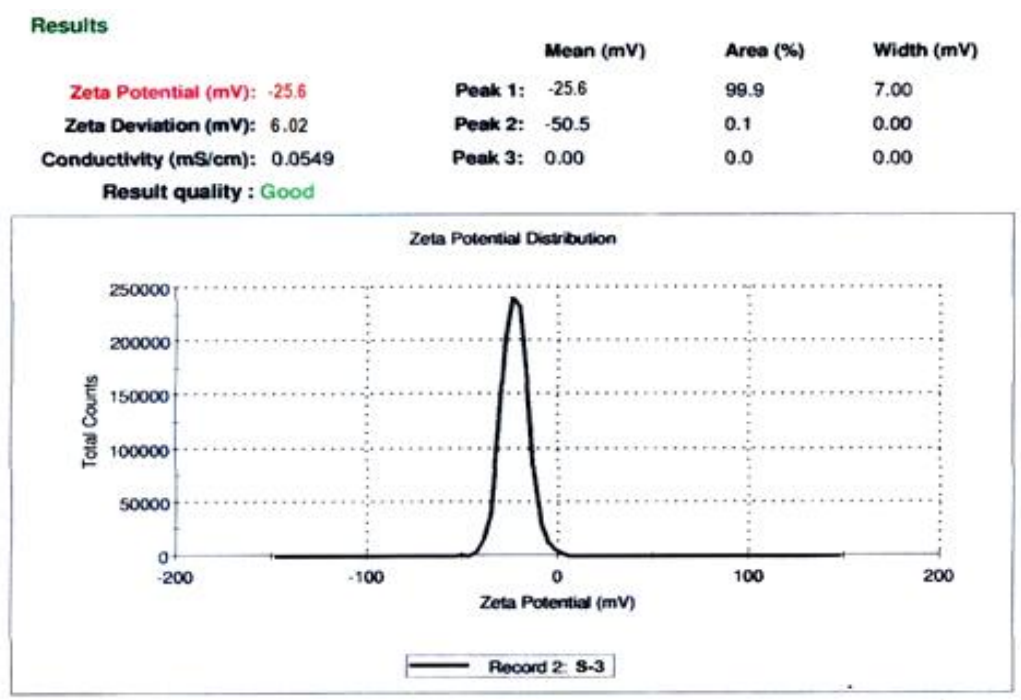

Fig. 3: Zeta potential of SLN-F3 Dispersion. 


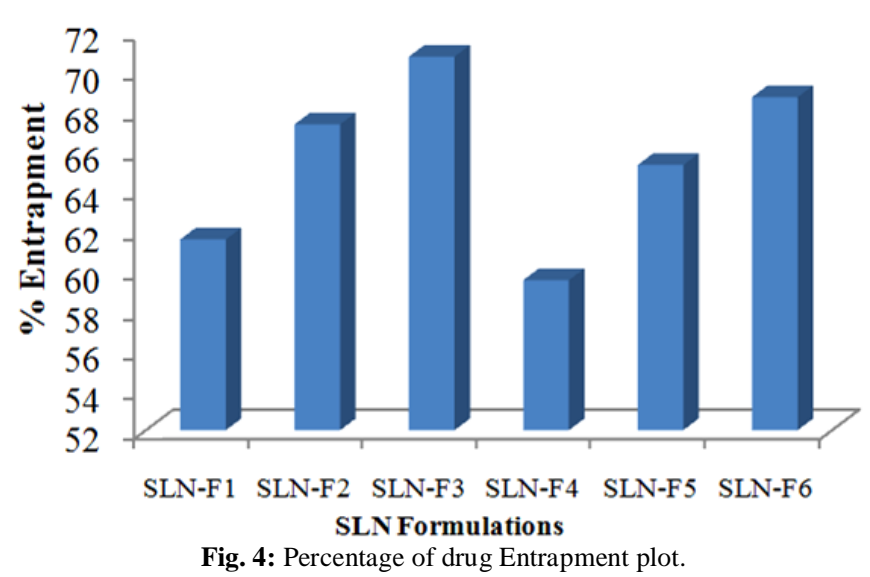

\section{Scanning Electron Microscopy}

SEM was used to obtain more information about particle size and shape of SLN dispersion. Further no sign of drug precipitation was observed inferring the stable nature of formed dispersion. The size of particle observed in micrograph is in agreement with data obtained by Malvern Mastersizer (Teeranachaideekul et al., 2007).

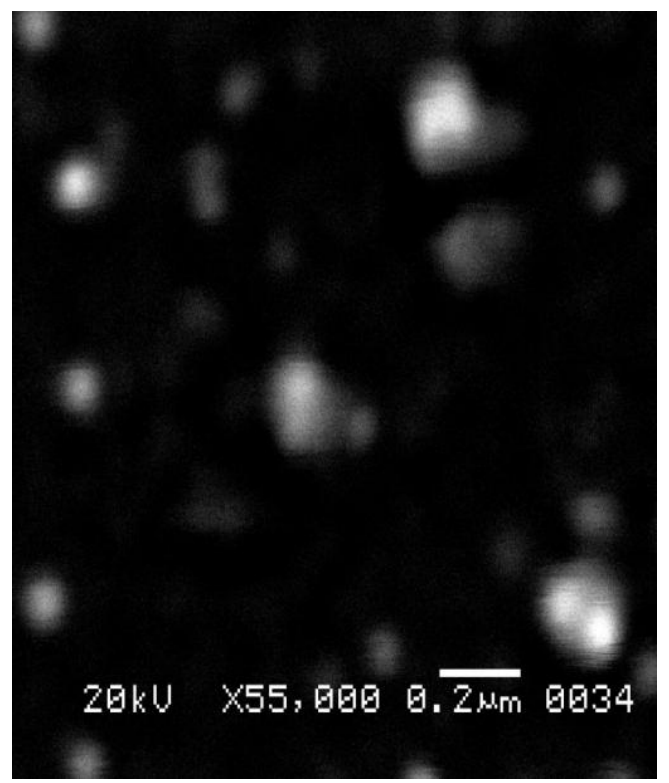

Fig. 5: SEM of SLN-F3 Dispersion at 55000X.

\section{FTIR Analysis}

The IR spectra of pure drug etoricoxib, SA+ Drug, Drug loaded SLN, are shown in Figure 3.18, 3.19, 3.20, 3.21 and 3.22 respectively. This result indicates that there is no chemical interaction between the SA and etoricoxib.

However, in the IR spectrum of etoricoxib loaded SLN (Fig. 6) peaks corresponding to etoricoxib disappear or buried in the peak of stearic acid indicating drug entrapment in lipid matrix as shown in (Fig. 8). The Etoricoxib due to high melting point have precipitated as core and the stearic acid may have formed the coating around the drug core as suggested from the above data. (Nasr et al., 2008).

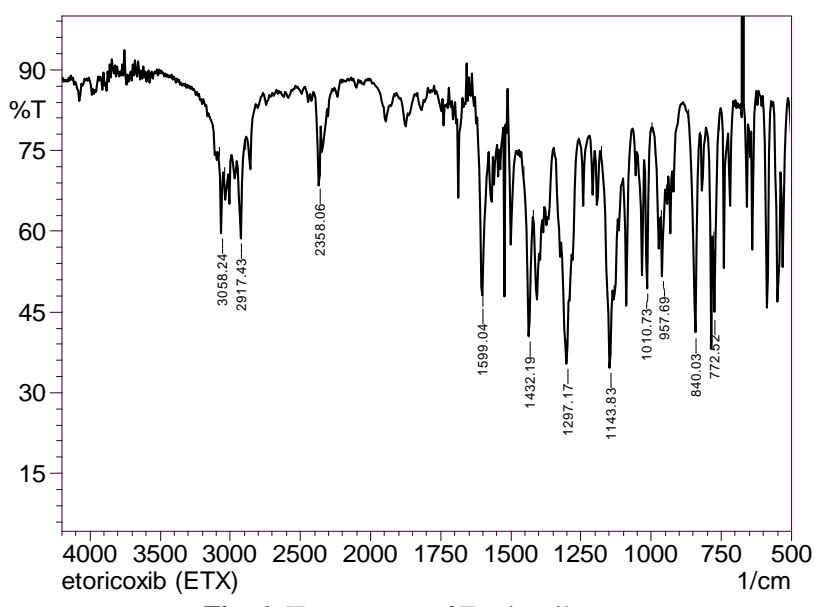

Fig. 6: IR spectrum of Etoricoxib.

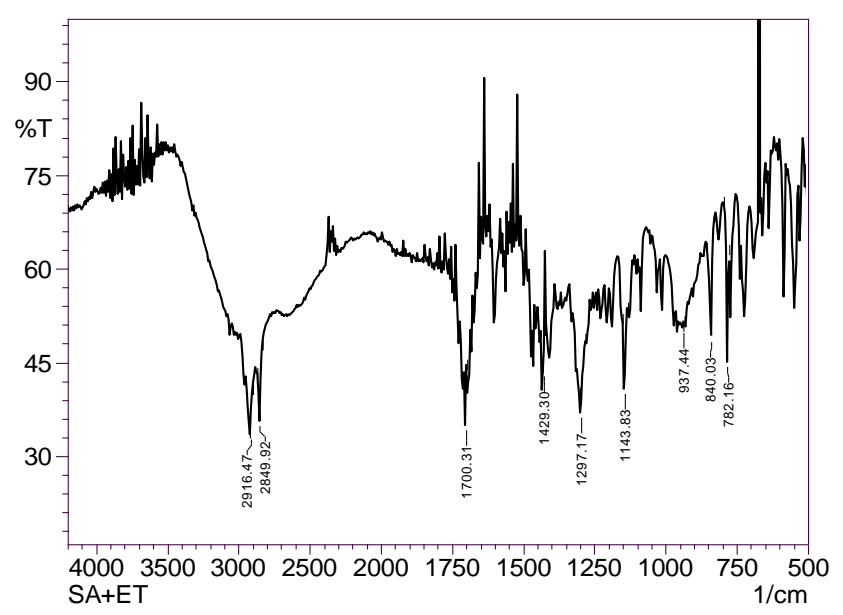

Fig. 7: IR spectrum of Stearic acid + Drug

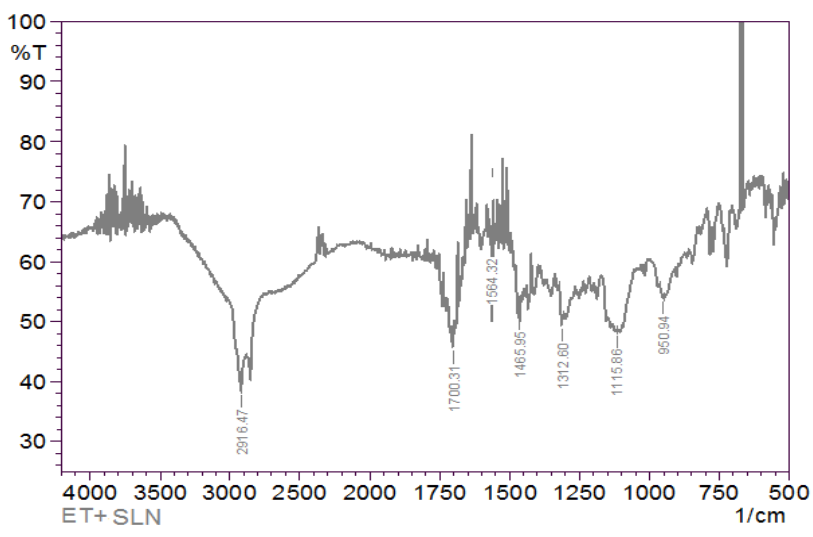

Fig. 8: IR spectrum of Drug loaded SLN.

\section{Differential Scanning Calorimeter Analysis (DSC)}

DSC is considered as a tool to investigate the melting behavior of crystalline materials like solid lipid nanoparticles. Blended matrix of lipid shows a melting point depression as compared to solid lipid. e.g. melting point of stearic acid was $67.81{ }^{\circ} \mathrm{C}$ but mixture of stearic acid and etoricoxib showed a melting point depression $66.78{ }^{\circ} \mathrm{C}$ (Table 4). Formulation SLN-F3 was chosen as a representative of etoricoxib SLN as it possessed 
the highest entrapment efficiency. DSC thermogram of etoricoxib showed endothermic peak at $136.12{ }^{\circ} \mathrm{C}$ as evident in (Fig. 9), which is the reported melting point of the drug. Drug loaded SLN showed a large endothermic peak at $59.78{ }^{\circ} \mathrm{C}$ (Fig. 10) and disappearance of the drug peak suggesting a molecular dispersion (lees amount of drug solubilize in lipid) of etoricoxib into the loaded SLN and that etoricoxib exists in amorphous state (Liquid state) rather than in crystalline state. (Nasr et al., 2008; Agrawal et al., 2010; Jia et al., 2010; Hou et al., 2003).

Table 4: DSC parameters of excipient and SLN dispersion.

\begin{tabular}{ccc}
\hline Sample & Onset $\left({ }^{\circ} \mathbf{C}\right)$ & Melting point $\left({ }^{\circ} \mathbf{C}\right)$ \\
\hline Etoricoxib & 133.20 & 136.12 \\
Stearic acid & 54.65 & 67.81 \\
SA+ Etori & 57.24 & 66.78 \\
DSLN & 50.00 & 59.78 \\
\hline
\end{tabular}

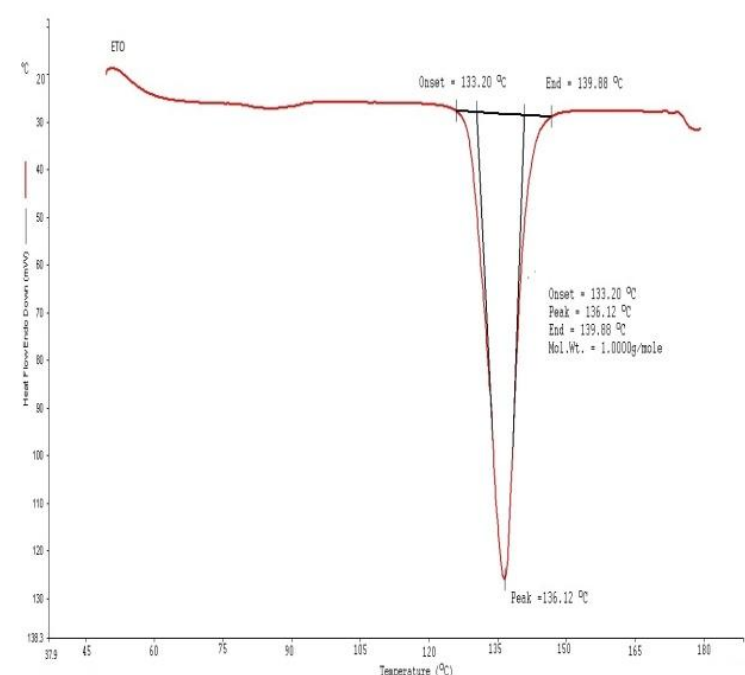

Fig. 9: DSC graph of Etoricoxib.

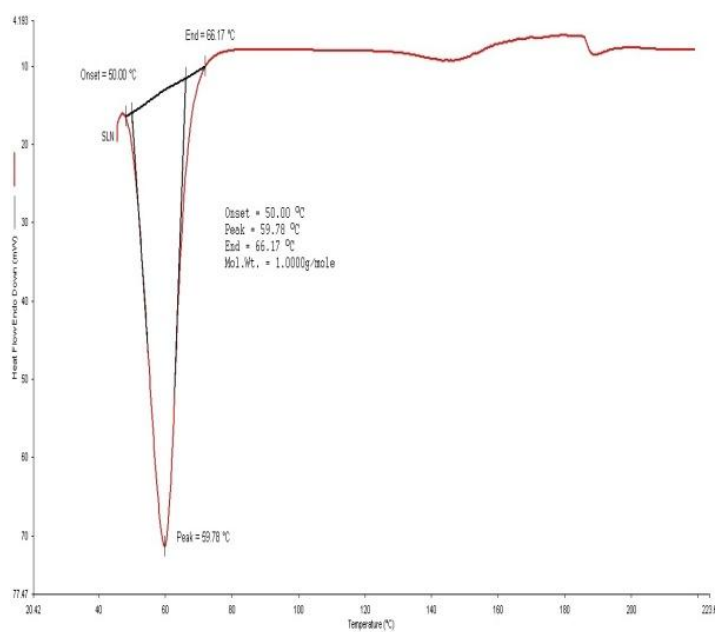

Fig. 10: DSC graph of Drug loaded SLN.

\section{Preparation \& Evaluation of Etoricoxib Loaded SLN based Gel}

Based on the particle size, entrapment efficiency, SLNF3 formulation having optimum physicochemical properties was selected for gel. SLN dispersion was incorporated into the gel. The physical appearance of drug loaded SLN gel was found to be offwhite in color, smooth in texture and translucent. All the formulation was found to be homogenous. All the formulated gel was evaluated for spreading diameter at $1 \mathrm{~min}$, as a measure of stiffness. The result showed that spreadibility coefficient of Carbopol SLN gel was somewhat equal to Hydroxypropylmethyl cellulose (HPMC) SLN gel.

Table 5: Spreadibility of SLN-F3C gel \& SLN-F3 HPMC gel.

\begin{tabular}{ccc}
\hline S. No. & $\begin{array}{c}\text { Spreadibility* } \\
(\mathbf{g . c m} / \mathbf{s e c})\end{array}$ & Formulation Code \\
\hline 1 & $206.947 \pm 14.520$ & SLN-F3 C \\
2 & $209.841 \pm 10.003$ & SLN-F3 HPMC \\
\hline
\end{tabular}

*Mean \pm S.D.

\section{In Vitro Release Study of SLN Gel}

In Vitro studies were performed to compare the release rate of the drug from the SLN gel formulation using carbopol and SLN gel using hydroxypropylmethylcellulose (HPMC), which was code named as SLN-F3C \& SLN-F3HPMC. The cumulative percentage release of etoricoxib from SLN based Gel were investigated for a period of 24 hours. Each sample was analyzed in triplicate.

Table 6: Drug release profile of SLN-F3C and SLN-F3HPMC.

\begin{tabular}{cccc}
\hline S.No. & Time $(\mathbf{h r})$ & \multicolumn{2}{c}{ \% Release of drug from SLN gel * } \\
\cline { 2 - 4 } & & SLN-F3HPMC & SLN-F3C \\
\hline 1 & 0.25 & $14.469 \pm 11.025$ & $6.900 \pm 0.289$ \\
2 & 0.50 & $17.322 \pm 2.018$ & $9.987 \pm 3.044$ \\
3 & 1.00 & $19.379 \pm 0.880$ & $14.239 \pm 3.096$ \\
4 & 2.00 & $21.088 \pm 1.683$ & $28.242 \pm 3.915$ \\
5 & 3.00 & $26.769 \pm 2.981$ & $37.771 \pm 2.711$ \\
6 & 4.00 & $30.718 . \pm 3.034$ & $41.356 . \pm 1.166$ \\
7 & 5.0 & $35.000 \pm 1.691$ & $44.835 \pm 0.893$ \\
8 & 6.0 & $40.972 \pm 3.295$ & $48.234 \pm 0.768$ \\
9 & 8.00 & $41.101 \pm 30.532$ & $56.829 \pm 4.064$ \\
10 & 12.0 & $53.459 \pm 3.547$ & $65.868 \pm 1.626$ \\
11 & 24.0 & $74.956 \pm 5.294$ & $82.791 \pm 3.696$ \\
\hline
\end{tabular}

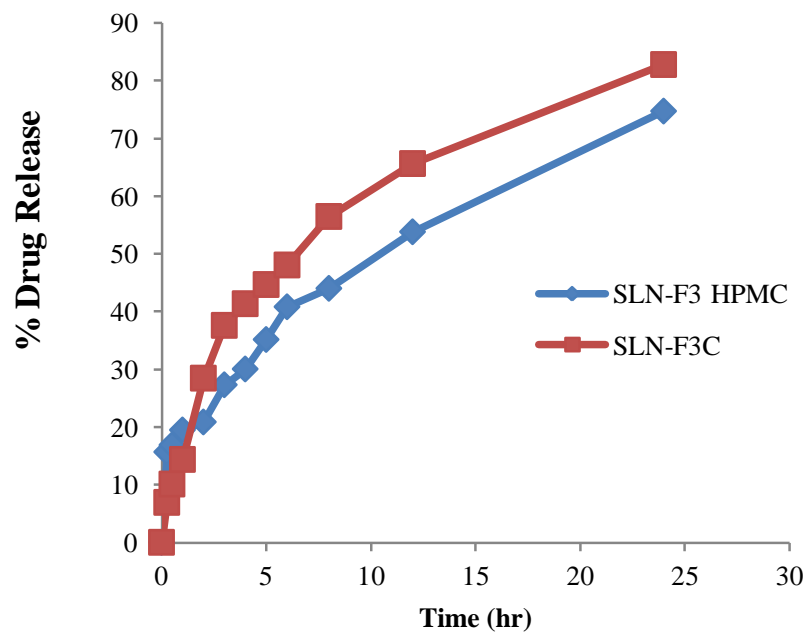

Fig. 11: Comparative drug release profile of SLN-F3C and SLN-F3HPMC. 


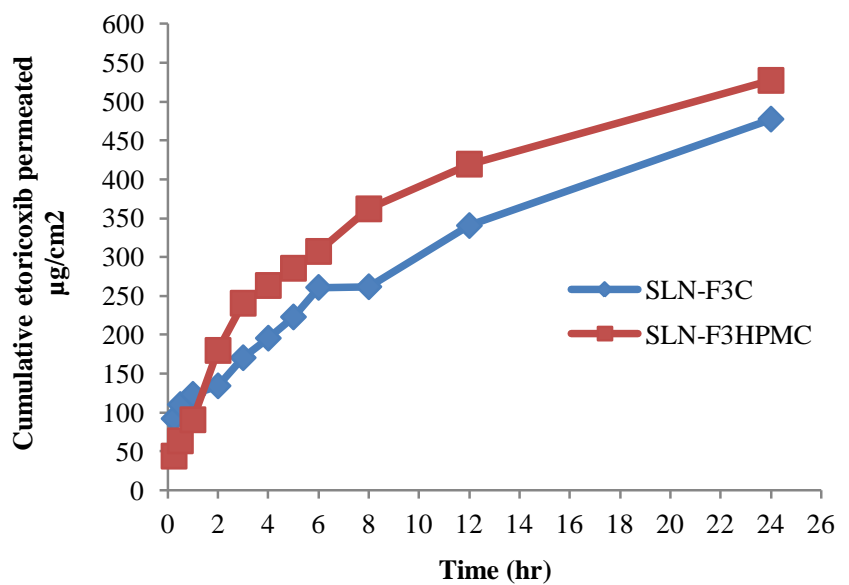

Fig. 12: Comparative drug permeation profile of SLN-F3C \&SLN-F3HPMC.

\section{PERMEATION DATA ANALYSIS}

Permeability parameters steady-state flux $\left(\mathrm{J}_{\mathrm{ss}}\right)$ was significantly increased in SLN-F3C formulation as compared with SLN-F3HPMC formulation. This is because SLN-F3C contains carbopol and HPMC is gummy in nature as compare to carbopol. The permeability parameters of both formulations are given in Table 7

Table 7: permeation data of SLN-F3C and SLN-F3HPMC.

\begin{tabular}{cc}
\hline Formulation code & Jss \pm S.D. $(\boldsymbol{\mu} \mathbf{g} / \mathbf{c m} \mathbf{2} / \mathbf{h r})$ \\
\hline SLN-F3HPMC & $19.892 \pm 1.934$ \\
SLN-F3C & $21.968 \pm 0.862$ \\
\hline
\end{tabular}

\section{RELEASE ORDER KINETICS STUDY}

Data obtained from In Vitro release studies were fitted to various kinetic equations to find out the mechanism of drug release from the gel formulation. The kinetic models used were zero order equation, first order equation, Higuchi model. From the release kinetics table it can be observed that the release of etoricoxib from the SLN- SLN-F3C exhibit Anomalous (non-Fickian) diffusion, and closely follows Korsmeyer-Peppas Model and also highly correlated with Higuchi Model. Whereas the release of Etoricoxib from the SLN-F3 HPMC exhibit Higuchi Model and closely follows Korsmeyer-Peppas Model.

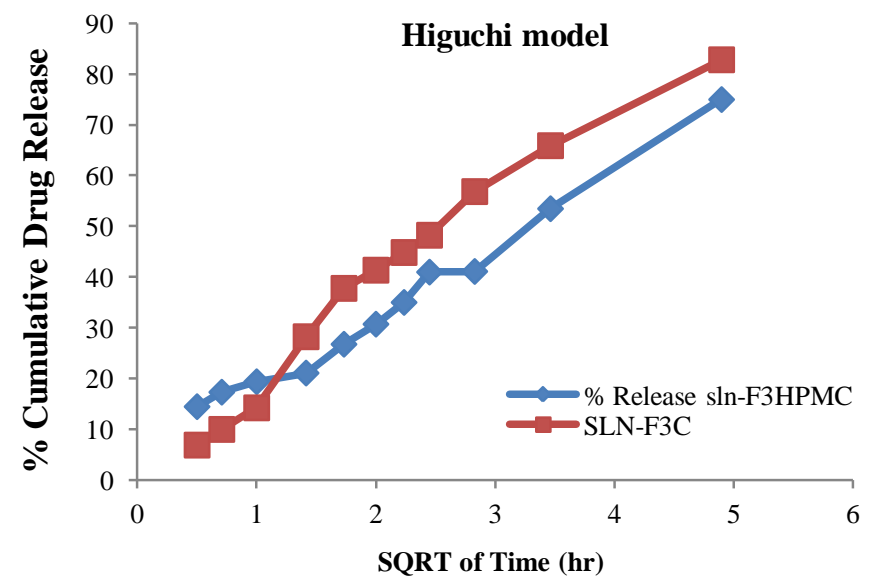

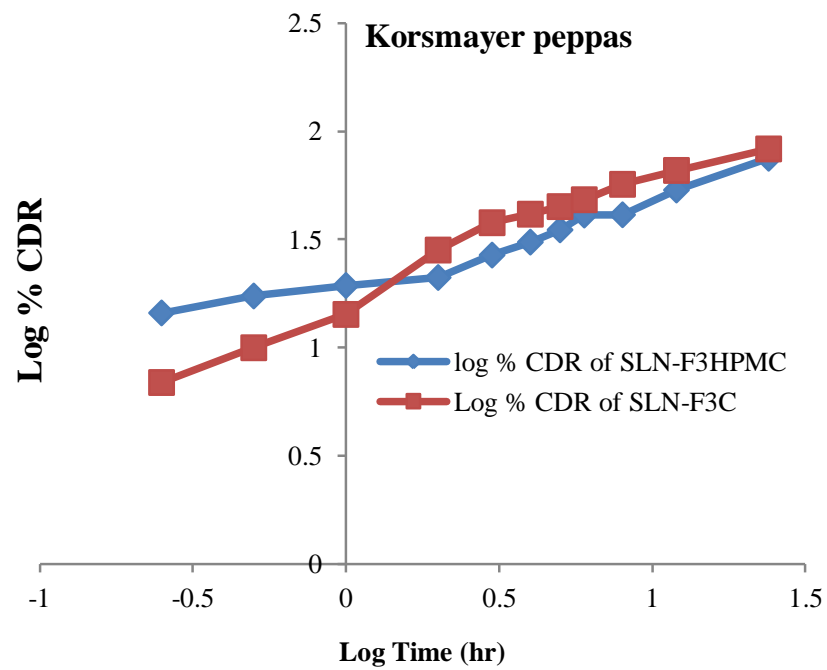

Fig. 13 \& 14: Comparative Higuchi \& Korsmeyer-pepas plot SLN-F3C and SLN- F3HPMC.

\section{CONCLUSION}

The Solid lipid nanoparticles were successfully developed for topical delivery of etoricoxib. SLN dispersions were prepared by melt emulsification and solidification at low temperature method. Physicochemical characterization including particle size, particle size distribution, Zeta potential, scanning electron microscopy, crystallinity study by DSC and in-vitro release profile were carried out. It was seen that increasing the stearic acid concentration led to higher entrapment and by increasing the concentration of tween 80 lead to smaller the particle size. In-vitro drug release pattern of SLN gel showed fast and control release. Immediate releases as well as sustained release both are of interest for topical application. Immediate release can be useful to improve the penetration of drug \& maintain the concentration work as loading dose, while sustained release supplied the drug over a prolonged period of time.

\section{ACKNOWLEDGEMENT}

The authors are thankful to Unison Pharmaceuticals, Baddi, INDIA, for providing gift sample of Etoricoxib.

\section{Financial support and sponsorship: Nil.}

Conflict of Interests: There are no conflicts of interest.

\section{REFERENCES}

Agrawal Y, Petkar K, Sawant K. Development, Evaluation and Clinical studies of Acitretin loaded Nanostructured Lipid Carriers for Topical Treatment of Psoriasis. Int J Pharm. 2010; 93-102.

Bhalekar M R, Pokharkar V, Madgulkar A, Patil, N, Patil N K. Preparation and Evaluation of Miconazole Nitrate-Loaded Solid Lipid Nanoparticles for Topical Delivery. AAPS PharmSciTech. 2009; 10(1).

Bhasker K, Anbu J. Lipid Nanoparticles for Transdermal Delivery of Flurbiprofen; Formulation, In-Vitro, Ex-Vivo and In-Vivo Studies. Lipid in Health and Disease. 2009; 8(6): 1-15.

Biswal B, Karna N, Nayak J, Joshi V. Formulation and Evaluation of Microemulsion based topical Hydrogel containing 
Lornoxicam. Journal of Applied Pharmaceutical Science. 2014; 4(12): 077-084.

Doktorovova S, Araujo J, Formulating fluticasone propionate in novel PEG-containing nanostructured lipid carriers (PEG-NLC). Colloids and Surfaces B: Biointerfaces. 2010; 75: 538-542.

Dongfei L, Sunmin J, Hong S, Shan Q, Juanjuan, L, Qing, Z. Diclofenac sodium-loaded solid lipid nanoparticles prepared by emulsion/solvent evaporation method. J Nanopart Res. 2010; DOI 10, 1007/s11051-010.

Edwards DA, Langer R. A Linear Theory of Transdermal Transport Phenomena. J.Pharm. Sci. 1994; 83: 1315-1334.

Ekambaram P, Hasan Abdul A Sathali, K Priyanka. Solid Lipid Nanoparticles: A Review. Sci. Revs. Chem. Commun. 2012; 2(1): 80-102.

Gonzalez E, Cruz C, Nicolas R, Egido J, Herrero B G. LongTerm Effects of Nonsteroidal Anti-Inflammatory Drugs on the Production of Cytokines and Other Inflammatory Mediators by Blood Cells of Patients with Osteoarthritis. Agents Actions. 1994; 41: 171-178.

Hou D, Xie C, Huang K, Zhu C. The Production and Characteristics of Solid Lipid Nanoparticles (SLNs). Biomaterials, 2003; 24: $1781-1785$

Jain P, Mishra A, Yadav SK, Patil, UK, Baghel U S. Formulation Development and Characterization of Solid Lipid Nanoparticles Containing Nimesulide. Int J of Drug Delivery Tech, 2009; 1(1): 24-27.

Jia L, Zhang D. Nanostructured Lipid Carrier for Parenteral Delivery of Silybin: Biodistribution and Pharmacokinetic Studies. Colloids and surface B: Biointerfaces. 2010; 80: 213-218.

Joshi M, Patravale V. Nanostructured Lipid Carrier (NLC) Based Gel of Celecoxib. Int. J.Pharm. 2008; 346:124-132.

Lala, R.R., Awari, N.G. Nanoemulsion-Based Gel Formulations of COX-2 Inhibitors for Enhanced Efficacy in Inflammatory Conditions. Appl Nanosci. 2014; 4: 143-151.

Lee J, Lee Y, Kim J, Yoon M, Choi W Y. Formulation of Microemulsion System for Transdermal Delivery of Aceclofenac. Arch Pharm Res. 2005; 28: 1097-102.

Mazumder B, Dey S, Bhattacharya S, Sarkar S, Mohanta B. Studies on Formulation and Characterization of Cellulose-Based Microspheres of Chlorpheniramine Maleate. Arch Pharm Sci\& Res. 2009; 1: 66-74.

Mukherjee S, Ray S, Thakur R.S. Solid Lipid Nanoparticles (SLN): A Modern Formulation Approach in Drug Delivery System. Indian Journal of Pharmaceutical Sciences. 2009; 71(4): 349-358.
Nasr M, Mansour S, Mortada ND. Lipospheres as Carriers for Topical Delivery of Aceclofenac: Preparation, Characterization and In Vivo Evaluation. AAPS PharmSciTech. 2008; 9(1).

Patel Dilip, Dasgupta Sandipan, Dey Sanjay, Roja Ramani Y, Ray Subhabrata, Mazumder Bhaskar. Nanostructured Lipid Carriers (NLC)-Based Gel for the Topical Delivery Of Aceclofenac: Preparation, Characterization, And In Vivo Evaluation. Sci Pharm. 2012, 80: 749-764.

Sachan N K, Bhattacharya A. Modeling and Characterization of Drug Release from Glutinous Rice Starch Based Hydrogel Beads for Control Drug Delivery. Int. J. of health research. 2009; 2(1): 93-99.

Sanad A R, Abdelmalak N S. Formulation of a Novel Oxybenzone-Loaded Nanostructured Lipid Carriers (NLCs). AAPS. PharmScitech. 2010.

Takemoto JK, Reynolds JK, Remsberg CM, Vega-Villa KR, Davies NM: Clinical Pharmacokinetic and Pharmacodynamic Profile of Etoricoxib. Clin Pharmacokinet. 2008; 47(11): 703-20.

Teeranachaideekul V, Boonme P, Souto E B, Muller R H, Junyaprasert V B. Influence of Oil Content on Physicochemical Properties and Skin Distribution of Nile Red-Loaded NLC. J Control Release. 2008; 128(2): 134-41.

Teeranachaideekul V, Souto E B, Junyaprasert V B, Mullerr H. Cetylpalmitate-Based NLC for Topical Delivery of Coenzyme Q10 Development, Physicochemical Characterization And In Vitro Release Studies. Euro Journal of Pharma and Biopharm. 2007; 67: 141-148.

Westesen, K. Novel Lipid-Based Colloidal Dispersions As Potential Drug Administration Systems: Expectations And Reality. Coll. Polym. Sci, 2000; 278(7): 608.

\section{How to cite this article:}

Kesharwani R, Sachan A, Singh S, Pate D. Formulation \& Evaluation of Solid Lipid Nanoparticle (SLN) Based Topical Gel of Etoricoxib. J App Pharm Sci, 2016; 6 (10): 124-131. 